\title{
Robotic surgery in gynecologic oncology
}

\author{
Pierre Lèguevaque $\cdot S$. Motton $\cdot$ F. Vidal $\cdot$ \\ M. Soulé Tholy • J. Hoff • D. Querleu
}

Received: 6 December 2010 / Accepted: 23 December 2010 / Published online: 19 February 2011

(C) Springer-Verlag 2011

\begin{abstract}
The goal of this paper is to review the current data documenting the advantages of robotic surgery over open or laparoscopic surgery. The aim of this study is to compare the complications and perioperative outcome of robotic surgery with open and laparocopic surgery, in gynecologic oncology. The terms radical robotic or robot- assisted hysterectomy in PubMed search lead to 41 references. We excluded one review of literature, ten studies with benign and malignant cases, eight cases reports, one letter to the editor. We kept the prospective studies and comparative studies (total abdominal hysterectomy (TAH) vs. total robotic hysterectomy (TRH), total laparoscopic hysterectomy (TLH) vs. TRH or TAH vs. TRH vs. TLH). The results are separated for endometrial cancers, early cervical cancers, pelvic and paraaortic lymph node dissections, radical parametrectomy and trachelectomy, and pelvic exenteration. The literature on robotic-assisted radical hysterectomy supports its safety and feasibility for the surgical management of early cervical cancer and endometrial cancer. However, the
\end{abstract}

P. Lèguevaque $\cdot \mathrm{S}$. Motton · F. Vidal $\cdot$ M. S. Tholy $\cdot$ J. Hoff General and Gynecologic Surgery, CHU Rangueil,

1 Avenue Jean Pouilhès,

31059 Toulouse Cedex 9, France

\section{Querleu}

Institut Claudius Regaud, Oncological Surgery,

20-24 rue du pont Saint Pierre,

31052 Toulouse Cedex, France

\section{P. Lèguevaque $(\bowtie)$}

Chirurgie Générale et Gynécologique, CHU Rangueil,

1 Avenue Jean Pouilhès,

31059 Toulouse Cedex 9, France

e-mail: leguevaque.p@chu-toulouse.fr results of a phase III randomized clinical trial testing the equivalence of outcomes after laparoscopic or robotic radical hysterectomy with abdominal radical hysterectomy are expected.

Keywords Robotic $\cdot$ Hysterectomy $\cdot$ Radical . Laparoscopy $\cdot$ Endometrial $\cdot$ Cervical cancer

\section{Background}

Total abdominal radical hysterectomy and total abdominal hysterectomy (TAH) has been the standard treatment for early stage cervical and endometrial cancer, respectively, for decades. Advances in laparoscopic instrumentation have made possible to safely perform hysterectomy and radical hysterectomy laparoscopically (total laparoscopic hysterectomy (TLH) and total laparoscopic radical hysterectomy (TLRH)), pelvic and aortic dissection, and even pelvic exenteration [1]

The latest advance in laparoscopic instrumentation has been the development of robotic-assisted surgery. One advantage of the robotic system compared to laparoscopy is the dual lens, $12 \mathrm{~mm}$ laparoscope that provides vivid 3-D images. The other advantage is the intra-abdominal articulation of the micro-instruments $2 \mathrm{~cm}$ from the tip. These articulations serve the same function of the human wrist and greatly add in the ability to suture and tie knots, and improve tissue dissection. Total robotic hysterectomy (TRH) with lymph node dissection and total robotic radical hysterectomy have been described since 2005 [2-4]. Transperitoneal and extraperitoneal pelvic and aortic lymph node dissection have also been described [5-7]. 


\section{Methods}

\section{Objectives}

Robotic surgery may overcome many of the difficulties associated with standard laparoscopic surgery of cervical and endometrial cancer. Improved vision, dexterity of instrumentation, and increased control of all instrumentation by the primary surgeon, may provide an advantage during unroofing and dissection of the distal ureter. The robotic-assisted laparoscopic surgery may also be advantageous during lymphadenectomy in some areas, cardinal ligament dissection, and suturing of the vaginal cuff.

However, although the advantages of robotic surgery seem obvious for the surgeon's comfort, the question of patient benefit is still open, considering that the major paradigm shift has been the advent of minimal invasive surgery in the field of oncology. Indeed, two levels of comparison are possible: robotic versus open surgery, robotic versus laparoscopic surgery. The goal of this paper is to review the current data documenting the advantages of robotic surgery over open or laparoscopic surgery.

\section{Data source}

A PubMed search has been carried out. The terms radical robotic or robot-assisted hysterectomy lead to 41 references. We excluded one review of literature, ten studies without distinction between benign and malignant cases, eight cases reports, and one letter to the editor. We kept the prospective studies and comparative studies (TAH vs. TRH, TLH vs. TRH or TAH vs. TLH vs. TRH).

\section{Review methods}

The evaluation of robotic radical hysterectomy should be complete, with the population characteristics, mean operative time, lymph node count, intra- and postoperative complications, conversion and transfusion rate, estimated blood loss, and length of stay.

Seventeen references were retrieved. Only studies clearly addressing the results by tumor site were included. Ten and seven papers were included for early cervical cancer and endometrial cancer, respectively.

\section{Findings}

Radical hysterectomy for early cervix carcinoma

Comparative studies are available (Tables 1 and 2). However, all were historical or open comparisons.
The first robotic hysterectomy was reported in 2005 [2]. Others authors published their early experience [3-8]. Fanning et al. [9] performed robotic radical hysterectomies in 20 consecutive stage IA-IIA cervical cancer patients. Even though the operative time seems to be long compared to other series, Fanning concluded that the improved vision and intra-abdominal articulation of the robot provide an advantage in performing the most difficult steps of radical hysterectomy, such as unroofing and dissection of the distal ureter. A retrospective clinical review of 10 stage Ia2-Ib1 cervical cancer patients who underwent TRH was published by Kim et al. [10] in 2008. The authors concluded that TRH for selected early cervical cancer cases is feasible and associated with low morbidity. Oleszczuk et al. [11] described a technique of vaginal robot-assisted radical hysterectomy in a prospective study in 12 patients. For the authors, the complication rate is lower than in their own TLH series, but the patient number is still relatively small for such conclusions.

Lowe [12] recently published the first multi-institutional study of TRH for early cervical cancer. He summarized the referenced data on TRH as compared to the referenced literature on TLH, and concluded that several surgical outcomes (estimated blood loss, mean operative time, node retrieval, and hospital stay) are equivalent and may be superior in some aspects for patients undergoing a roboticassisted approach. For the authors, a background in laparoscopy was not a prerequisite to becoming a successful robotic surgeon but may shorten the learning curve in the adoption phase of robotics.

In 2007, a pilot case-control study designed to evaluate the feasibility and efficacy of TRH and bilateral pelvic lymph node dissection for early cervical cancer was reported by Sert et al. [13]. Seven consecutive patients were compared to eight patients treated by conventional TLH. There were no statistically significant differences observed in the two groups in regard of mean operative time, number of lymph nodes, and length of resected parametrial tissues whereas significantly less bleeding and shorter hospital stay were described in the TRH group. However, the small sample size results in a low power of the statistical conclusions in this study. Gradually, the casecontrol studies showed a larger number of cases [14, 15]. Ko et al. [14] published a TAH/TRH comparison. The mean operative time, estimated blood loss, and length of stay were significantly different with better results in robotic approach. In 2009, Maggioni [15] published a similar comparison with the same results.

Nezhat et al. [16] compared the intra-operative, pathologic, and post-operative outcomes of TRH to TLH in 13 and 21 patients with early stage cervical cancer, respectively. No statistical differences were observed regarding operative time (323 vs. $318 \mathrm{~min}$ ), estimated blood loss 
Table 1 Review of literature: comparative studies of robotic assisted hysterectomy in early cervical cancer: population characteristics, operative time, and lymph nodes count

\begin{tabular}{|c|c|c|c|c|c|c|c|c|}
\hline Authors & $\begin{array}{l}\text { Year of } \\
\text { publication }\end{array}$ & Method & Methodology & $N$ & $\begin{array}{l}\text { Mean } \\
\text { age }\end{array}$ & Mean BMI & $\begin{array}{l}\text { Mean } \\
\text { operative } \\
\text { time (min) }\end{array}$ & Lymph nodes \\
\hline Sert [13] & 2007 & TLH/TRH & $\mathrm{CC}$ & $7 / 8$ & $45 / 41$ & $22.5 / 24.6$ & $300 / 241(\mathrm{NS})$ & 15/13 (NS) \\
\hline Ko [14] & 2008 & TAH/TRH & $\mathrm{HC}$ & $32 / 16$ & $41.7 / 42.3$ & $26.6 / 27.6$ & $219 / 290(\mathrm{~S})$ & $17.1 / 15.6(\mathrm{NS})$ \\
\hline Nezhat [15] & 2008 & TLH/TRH & PSOC & $30 / 13$ & $46.8 / 54.8$ & - & $318 / 323$ (NS) & $31 / 25(\mathrm{NS})$ \\
\hline Fanning [16] & 2008 & TRH & $\mathrm{RS}$ & 20 & 44 & - & 390 & 18 \\
\hline Kim [17] & 2008 & TRH & $\mathrm{RS}$ & 10 & 49.9 & - & 207 & 27.6 \\
\hline $\begin{array}{c}\text { Boggess } \\
\text { [18] }\end{array}$ & 2008 & TAH/TRH & PSOC & $49 / 51$ & $\begin{array}{l}41.9 / 47.4 \\
\text { (S) }\end{array}$ & $26.1 / 28.6(\mathrm{NS})$ & $248 / 211(\mathrm{~S})$ & $23.3 / 33.8(\mathrm{~S})$ \\
\hline $\begin{array}{c}\text { Magrina } \\
\text { [19] }\end{array}$ & 2008 & $\begin{array}{l}\text { TAH/TLH/ } \\
\text { TRH }\end{array}$ & $\mathrm{CC}$ & $\begin{array}{c}35 / 31 / \\
27\end{array}$ & $\begin{array}{l}50.9 / 54.9 / \\
50\end{array}$ & $27.3 / 26.8 / 27.2$ & $\begin{array}{l}166 / 220 / 189 \\
(\mathrm{~S})\end{array}$ & $\begin{array}{l}27.7 / 25.9 / 25.9 \\
\text { (NS) }\end{array}$ \\
\hline $\begin{array}{l}\text { Maggioni } \\
{[20]}\end{array}$ & 2009 & TAH/TRH & $\mathrm{CC}$ & $40 / 40$ & $\begin{array}{l}49.8 / 44.1 \\
(\mathrm{~S})\end{array}$ & 23.6/24.1 (NS) & 200/272 (S) & $26.2 / 20.4(\mathrm{NS})$ \\
\hline $\begin{array}{l}\text { Oleszczuk } \\
\text { [21] }\end{array}$ & 2009 & VRARH $^{\mathrm{a}}$ & PS & 12 & 44 & 24 & 356 & 40 \\
\hline Lowe [12] & 2009 & MI TRH ${ }^{\mathrm{b}}$ & PS & 42 & 41 & 25.1 & 215 & 25 \\
\hline
\end{tabular}

TAH Total abdominal radical hysterectomy, TLH total laparoscopic radical hysterectomy, TRH total robot-assisted radical hysterectomy, $S$ significant difference or NS no significant difference

${ }^{a}$ Vaginal robot-assisted radical hysterectomy

${ }^{\mathrm{b}}$ Multi-institutional total radical robot assisted hysterectomy

(157 vs. $200 \mathrm{ml})$, and mean pelvic nodes count ( 25 vs. 31$)$. There were no recurrences in either group with a mean follow-up time of 12 months in the robotic group and 29 months in the laparoscopic group. Their conclusion was that robotic radical hysterectomy appears to be equivalent to TLH with respect to operative time, blood loss, hospital stay, and oncologic outcome.

Boggess et al. [17] published a case-control study of robotic-assisted type III radical hysterectomy with pelvic lymph nodes dissection performed in 51 patients compared with 49 patients who underwent TAH. The results of this study demonstrate that TRH with pelvic lymph node dissection provides comparables, if not preferable, lymph node dissection over TAH. The robotic approach is associated with lower blood loss and shorter length of stay, in comparison with open approach. Of significant importance is the comparison of the complication rate that was seen in this study of TRH $(7.8 \%)$ in comparison with the control cohort of TAH $(16.3 \%)$. The authors give evidence that patients benefits that are associated with TRH and that experience with a laparoscopic approach is not necessary in moving to a robotic approach.

Magrina et al. [14] compared the TAH, TLH, and TRH: the results of this study are consistent with other studies

Table 2 Review of literature: studies of robot assisted hysterectomy in early cervical cancer: complications and outcomes

\begin{tabular}{|c|c|c|c|c|c|c|}
\hline Authors & $\begin{array}{l}\text { Intraoperative } \\
\text { complications (\%) }\end{array}$ & $\begin{array}{l}\text { Post operative } \\
\text { complications (\%) }\end{array}$ & $\begin{array}{l}\text { Estimated blood } \\
\text { loss }(\mathrm{ml})\end{array}$ & $\begin{array}{l}\text { Transfusion rate } \\
(\%)\end{array}$ & $\begin{array}{l}\text { Conversion } \\
\text { rate }(\%)\end{array}$ & $\begin{array}{l}\text { Length of stay } \\
\text { (days) }\end{array}$ \\
\hline Sert B [13] & $14.3 / 14.3$ (NS) & 28.5/14.5 (NS) & 160/71 (S) & $0 / 0$ & $0 / 0$ & $8 / 4$ \\
\hline Ko [14] & $3.1 / 0$ (NS) & $21.8 / 18.7$ & 665/82 (S) & $31.2 / 6.3(\mathrm{NS})$ & 0 & 4.9/1.7 (S) \\
\hline Nezhat [15] & 6.66/15.4 (NS) & $6.6 / 7.7$ & 200/157 (NS) & - & - & 3.8/2.7 (NS) \\
\hline Fanning J [16] & 5 & 5 & 300 & 0 & 0 & 1 \\
\hline Kim YT [17] & 0 & 10 & 355 & 0 & 0 & 7.9 \\
\hline Boggess [18] & $7.8 \% / 16.3 \%(\mathrm{~S})$ & 16.3/7.8 (NS) & 96.5 & 0 & 0 & 1 \\
\hline Magrina [19] & 6/3/0 (NS) & 9/6/7 (NS) & 208/443/133 (S) & $9 \% / 0 \% / 4 \%$ (NS) & $0 / 0$ & $2.4 / 3.6 / 1.7$ \\
\hline Maggioni [20] & $12.5 / 5$ (NS) & $52.5 / 30(\mathrm{NS})$ & $221.8 / 78(\mathrm{~S})$ & $22.5 \% / 7.5 \%$ & 0 & 5/3.7 (S) \\
\hline Oleszczuk [21] & 0 & 0 & 123 & 0 & 0 & $4-10$ \\
\hline Lowe [12] & 4.8 & 12 & 50 & 0 & $2.4 \%$ & 1 \\
\hline
\end{tabular}

$S$ significative difference or $N S$ no significant difference 
demonstrating patients' benefits with the use of laparoscopy as compared to laparotomy for cervical cancer. However, while previous reports demonstrated longer operating times for laparoscopy as compared to laparotomy [18-21], this study showed similar operating times for TRH and TAH, which were significantly shorter as compared to TLH. Two additional differences were noted between TRH and TLH patients: reduced blood loss among patients in the radical subgroup and a shorter hospital stay in the modified radical. Otherwise, laparoscopy and robotic groups compared favorably, and both offered greater patients benefits as compared to laparotomy patients.

\section{Main results}

In conclusion, the literature on robotic-assisted radical hysterectomy supports its safety and feasibility for the surgical management of early cervical cancer. Both robotic and laparoscopic radical hysterectomy have been shown to have advantages for patients over the open approach in terms of blood loss, blood transfusions, complications, and length of hospital stay, with the exception of prolonged operation. The available literature suggests that robotic technology may be associated with improved operative outcomes as compared to a traditional laparoscopic approach for radical hysterectomy but no randomized data has been published. Similar recurrence and cure rates have been reported when comparing the results of both techniques. Long-term follow-up data is not available at this time regarding recurrence rates and overall survival. The results of a phase III randomized clinical trial testing the equivalence of outcomes after laparoscopic or robotic radical hysterectomy with abdominal radical hysterectomy in patients with early cervical cancer are expected [22].

\section{Endometrial cancer staging}

The first studies were comparative, with historical or open comparison. The open studies presented a low number of patients whereas the case-control studies presented some data with greater statistical power.

Seven publications on TRH and endometrial cancer were selected. The results are presented in Tables 3 and 4 .

The first study on endometrial cancer robotic surgery is published by Veljovich et al. [23] in 2008. Analysis of this study suggests that robotic surgery offers the advantages of decreased blood loss and length of stay at the expense of longer operating times. The author anticipates that with more experience with the technology, he will decrease the robotic operative times. The additional $2 \mathrm{~h}$ to complete surgical staging is probably the result of low laparoscopic volume before initiating a robotic program.

Bell et al. [24] published a similar study. Data indicates that robotics or standard laparoscopic staging were about $1 \mathrm{~h}$ longer than laparotomy. These data are similar to several other investigators $[25,26]$ who compared standard TLH to TAH. The perioperative complications are significantly higher for laparotomy procedures than compared to robotic surgery. Furthermore, robotic surgery had resulted in fewer complications than standard laparoscopy [25, 27]. This data demonstrate a significant decrease in hospital stay for both TLH and TRH compared to TAH. The length of stay is directly related to the cost: in this study, both charge data and cost data rank laparotomy as the most expensive modality followed by robotic and laparoscopy.

The study published by Denardis et al. [28] included 56 patients with endometrial cancer who underwent TRH with lymphadenectomy. Robotics data were compared to 106 serially treated patients who were operated by TAH before robotic program. The results are similar to other studies, with a lower rate of perioperative complications, blood loss, transfusion rate, and length of stay. Mean operative time for the TRH cases was more than double that of the open cases, but the TAH mean operative time (79 min) is significantly less than that reported by others authors ranging from 102 to $220 \mathrm{~min}$. Robotic assistance adds a minor amount of time with docking and undocking of the patient-side robotic platform.

Boggess et al. [29] noted a significant reduction in operative time as progress was made through the learning curve, such that the initial robotic surgeries for endometrial cancer required $214 \mathrm{~min}$ and the most recent published cases required only $163 \mathrm{~min}$. In a comparative study of three surgical methods for hysterectomy with staging for endometrial cancer (TAH, TLH, and TRH), Boggess concluded that TRH with staging is feasible and preferable over TAH and may be preferable over TLH in endometrial cancer. Further study is necessary to determine long-term oncologic outcomes. Indeed, the TRH and TLH cohorts were comparable with respect to both conversions to TAH and perioperative complications. There were also significantly fewer postoperative complications, when compared with the TAH cohort and a clinically meaningful trend towards fewer post-operative complications, when compared with the TLH cohort. Unlike most studies, Boggess report an increase in the lymph node yield in the robotic cohort compared with both the TAH and TLH cohorts, and a shorter operating time in the robotic cohort, compared with the laparoscopic cohort. For the authors, this in part is due to optimization of port placement that requires a single docking of the robotic instrument and greater ease in overcoming anatomic barriers with robotic assistance, which allows for a more comprehensive lymphadenectomy, such as when 
Table 3 Review of literature: studies of robotic assisted hysterectomy in endometrial cancer: population, mean operative time and lymph nodes count

\begin{tabular}{|c|c|c|c|c|c|c|c|c|}
\hline Authors & Year & Methods & Methodology & $N$ & $\begin{array}{l}\text { Mean Age } \\
\text { (years) }\end{array}$ & BMI & $\begin{array}{l}\text { Mean operative time } \\
(\mathrm{min})\end{array}$ & $\begin{array}{l}\text { Lymph nodes } \\
(n)\end{array}$ \\
\hline $\begin{array}{l}\text { Veljovich } \\
\text { [23] }\end{array}$ & 2008 & $\begin{array}{l}\text { TAH/TLH/ } \\
\text { TRH }\end{array}$ & $\mathrm{HC}$ & $131 / 4 / 25$ & $63 / 54 / 59.5$ & $\begin{array}{l}32.2 / 24.6 / \\
27.6\end{array}$ & $139 / 255 / 283$ & $\begin{array}{l}13.1 / 20.3 / 17.5 \\
\text { (NS) }\end{array}$ \\
\hline Bell [24] & 2008 & $\begin{array}{l}\text { TAH/TLH/ } \\
\text { TRH }\end{array}$ & $\mathrm{RS}$ & $40 / 30 / 40$ & $72 / 68 / 63$ & $31 / 31 / 33$ & $\begin{array}{l}\text { 108/171/184 (S and } \\
\text { NS) }\end{array}$ & $14.9 / 17.1 / 17$ \\
\hline $\begin{array}{l}\text { Denardis } \\
\text { [28] }\end{array}$ & 2008 & TAH/TRH & $\mathrm{HC}$ & 56 & $63 / 59$ & $34 / 29$ & 79/177 (S) & 18/19 (NS) \\
\hline $\begin{array}{l}\text { Boggess } \\
{[29]}\end{array}$ & 2008 & $\begin{array}{l}\text { TAH/TLH/ } \\
\text { TRH }\end{array}$ & PSOC & $\begin{array}{c}138 / 81 / \\
103\end{array}$ & $64 / 62 / 61.9$ & $\begin{array}{l}34.7 / 29 / \\
32.9\end{array}$ & $146 / 213 / 191$ & $14.9 / 23.1 / 32.9$ \\
\hline $\begin{array}{l}\text { Hoekstra } \\
{[30]}\end{array}$ & 2009 & $\begin{array}{l}\text { TAH/TLH/ } \\
\text { TRH }\end{array}$ & $\mathrm{HC}$ & $26 / 7 / 32$ & $56 / 59 / 62$ & $\begin{array}{l}37 / 31 / 29 \\
(\mathrm{~S})\end{array}$ & 202/270/195 (S) & $17 / 16 / 17$ \\
\hline $\begin{array}{l}\text { Lowe P } \\
{[31]}\end{array}$ & 2009 & $\mathrm{MI}^{\mathrm{a}} \mathrm{TRH}$ & PS & 405 & 62.2 & 32.4 & 170 & 15.5 \\
\hline $\begin{array}{c}\text { Seamon } \\
{[33]}\end{array}$ & 2009 & TLH/TRH & $\mathrm{PS}$ and $\mathrm{HC}$ & $76 / 105$ & 57/59 (NS) & $\begin{array}{l}28.7 / 34.2 \\
(\mathrm{~S})\end{array}$ & 287/242 (S) & $22 / 21$ \\
\hline
\end{tabular}

$T A H$ total abdominal radical abdominal hysterectomy, $T L H$ total laparoscopic radical hysterectomy, $T R H$ total robot-assisted radical hysterectomy, $S$ significative difference or NS no significant difference, $C C$ case-control study, $H C$ historical comparison, $P S O C$ prospective study (without randomization) and open comparison, $R S$ retrospective study, $P S$ prospective study

${ }^{a}$ Multi-institutional total radical robot assisted hysterectomy

obtaining the left periaortic lymph nodes. In the Boggess experience of 103 patients, the surgeons have optimized the port placement to require docking of the robot only once to complete the entire procedure, lymphadenectomy and TRH, thus simplifying the operation, decreasing operative time, and making it more generalizable.

Average estimated blood loss for the TRH group was three times less than that seen in the TAH group and one half that of the TLH group. Patients in the TRH group had a shorter length of stay, when compared with both the TAH and TLH groups. From a clinical standpoint, the estimated blood loss and length of stay results from both the TLH and TRH cohorts were excellent. However, the surgeons in this study had extensive previous laparoscopic experience and still saw significant improvements after the implementation of the robotics program.
In 2009, Hoekstra [30] report the impact of a new robotic surgery program on perioperative outcomes. Median operative time for robotics and laparotomy was significantly less than for laparoscopy. There was no significant difference in lymph nodes yields between the three groups. TRH was associated with significantly less blood loss and lower complication rates compared to the TAH group. Practice management of endometrial cancer transitioned from a predominantly open approach $(5.6 \%$ TLH, 94.4\% TAH) to laparoscopy (11\% TLH) and robotics (49\% TRH) within 12 months.

The first multi-institutional experience [31] with TRH for endometrial cancer has been recently published by Lowe. The strength of this study is that it allows for analysis and evaluation of data from multiple institutions with surgeons of various levels of experience and expertise

Table 4 Review of literature: studies of robotic assisted hysterectomy in endometrial cancer: complications and outcomes

\begin{tabular}{|c|c|c|c|c|c|c|}
\hline Authors & $\begin{array}{l}\text { Intraoperative } \\
\text { complications (\%) }\end{array}$ & $\begin{array}{l}\text { Postoperative } \\
\text { complications (\%) }\end{array}$ & $\begin{array}{l}\text { Estimated blood } \\
\text { loss (ml) }\end{array}$ & $\begin{array}{l}\text { Transfusion } \\
\text { rate }(\%)\end{array}$ & $\begin{array}{l}\text { Conversion } \\
\text { rate }(\%)\end{array}$ & $\begin{array}{l}\text { Length of stay } \\
\text { (days) }\end{array}$ \\
\hline Veljovich [23] & - & - & $197 / 75 / 66^{\mathrm{a}}(\mathrm{S})(\mathrm{NS})$ & - & 7.4 & $5.3 / 1.7$ \\
\hline Bell [24] & $2.5 / 3.3 / 0$ & $25 / 23 / 7.5$ & $316 / 253 / 166(\mathrm{~S}$ and $\mathrm{NS})$ & $15 / 10 / 5$ & - & $4 / 2 / 2.3^{\mathrm{a}}$ \\
\hline Denardis [28] & $20.8 / 3.6$ & 16.1 & 241/105 (S) & $8.5 / 0$ & 5.4 & $3.2 / 1$ \\
\hline Boggess [29] & $0.7 / 3.7 / 1$ & 28.9/9.9/4.9 & $266 / 145 / 74.5$ & $1.5 / 2.5 / 1$ & $-4.9 / 2.9$ & $4 / 4 / 1.2 / 1^{\mathrm{a}}$ \\
\hline Hoekstra [30] & $23 / 28.5 / 6.2^{\mathrm{a}}$ & $46 / 0 / 12.5^{\mathrm{a}}$ & $500 / 150 / 50(\mathrm{~S})$ & - & $28.5 / 3.1$ & $3 / 1 / 1^{\mathrm{a}}$ \\
\hline Lowe P [31] & 3.5 & 14.6 & 87.5 & - & 6.7 & 1.8 \\
\hline Seamon [33] & 2.6/3.8 (NS) & $3.9 / 1.9(\mathrm{NS})$ & $88 / 200(\mathrm{~S})$ & $3 / 18(\mathrm{~S})$ & $12 / 26(\mathrm{~S})$ & $1 / 2$ \\
\hline
\end{tabular}

$S$ significant difference or NS no significant difference

${ }^{\text {a }}$ Significantly different between the open and both robotic and TLH groups, no difference between TLH and TRH groups 
with TRH. Each surgeon had performed finally more than 50 robotic surgeries at the time of data analysis. In comparison with the preliminary results of the Lap2 trial of GOG (Walker J), robotic surgery seems at least equivalent if not superior to laparoscopy in several perioperative outcomes. When compared with TAH, a robotic surgical approach has demonstrated an improvement in perioperative outcomes with the exception of operative time in the studies of Boggess, Hoekstra, and Denardis. Although precedent articles primarily represent single institution or single surgeon experiences, the date are very promising and would suggest that a robotic approach is preferable to an open approach and possibly a laparoscopic approach.

The remarkable element of this study [32] is the varying degrees of prior laparoscopic experience among the surgeons before they adopted robotics into their practices. This data suggest that robotic technology may level the playing field between the novice and expert minimally invasive surgeon when applied to complex operations such as endometrial cancer or early cervical cancer staging. Based on these data, the authors feel confident that a strong background in laparoscopy is not a requirement to becoming a successful robotic surgeon.

In that report such as the study of Bell [24], the cost of robotic system was included in the cost analysis for robotic surgery. The total average cost was reported as follows: TAH, $\$ 12,943$; TLH, $\$ 7,569$; and TRH, $\$ 8,212$. There was no statistically significant difference in costs between robotic and laparoscopic approach $(p=0.06)$. Both minimally invasive approaches cost significantly less than an open approach $(p=0.001)$. However, robotics was associated with less perioperative morbidity and quicker return to normal activity.

Seamon published [33] recently the Ohio State University's experience in TRH for endometrial cancer. The data are similar to precedent studies in term of mean operative time, lymph nodes count, perioperative complications, estimated blood loss, and length of stay. The remarkable element of this study is the report of robotics learning curve. Robotics may offer a shorter learning curve for minimally invasive surgery. When compared with laparoscopy, the robotics platform enables the surgeons to more readily transfer open techniques to a minimal-access setting. For robotic hysterectomy pelvic aortic lymphadenectomy for endometrial cancer, proficiency for Seamon is approximately 20 cases. The most surgeons learning robotic surgery have experience with laparoscopic endometrial cancer staging: unlike the learning curve for laparoscopy $[32,34-36]$ in which there is a decreased number of lymph nodes as well as an increased estimated blood loss noted during the initial adoption of the procedure, Seamon did not find a statistically significant difference in the robotic outcomes. The authors noted a significant improvement in times, as experience increased, without compromise in comprehensive staging.

Pelvic and paraaortic lymph node dissection, transperitoneal approach

Laparoscopic pelvic and paraaortic lymph node staging is widely used in patients with advanced cervical cancer prior to initiation of primary chemoradiotherapy [37-40].

An extended pelvic and paraaortic lymphadenectomy can reliably and safely be performed robotically in the management of gynecological malignancies. The robot aids in performing a meticulous dissection and in adhering to sound oncologic principles. For the robotic approach data are available [28, 41, 42] for both pelvic and paraaortic lymphadenectomy performed during staging procedure for endometrial, cervical, or early ovarian cancers. Data are available [37, 43-45] for the laparoscopic approach in terms of safety and feasibility.

The relatively low yield of robotic paraaortic lymphadenectomy with the robot as well as the difficulty of reaching the para-aortic nodes above the inferior mesentery artery must be noticed. No study showed an increased count of lymph nodes in robotic approach in comparison with laparoscopic approach and no randomized data has been published.

Paraaortic lymph node dissection, extraperitoneal approach

Extraperitoneal paraaortic laparoscopic lymphadenectomy is preferable to reduce the risks of adhesions prior to chemoradiotherapy and for obese patients where the transperitoneal approach is sometime impossible. Vergote [46] reported recently on five patients with stage $\mathrm{IIb}-\mathrm{IIIb}$ cervical carcinoma undergoing robotic retroperitoneal paraaortic lymphadenectomy. For the authors, the procedure was technically easier to perform than with the classical retroperitoneal approach. However, it should be noted that the authors limited the template of dissection to the lower paraaortic area. The number of paraortic lymph nodes removed ranges from 7 to 12 , the operating time ranges from 60 to $139 \mathrm{~min}$ with one intraoperative complication. In comparison, during a laparoscopic extraperitoneal lymphadenectomy [37], the average duration is $125.9 \mathrm{~min}$ and the average number of lymph nodes is 20.7 , which is much higher. It must be recalled that the left paraaortic supramesenteric area can be involved alone in cervical and ovarian cancers [47, 48]. Only papers [49] referring to full aortic dissection are potentially relevant.

The main difficulty of robotic approach is the accessibility in one docking to infra- and supra-mesenteric lymph nodes. According to the preliminary experience of Vergote 
[46], we believe the da Vinci robot offers advantages due to the steady 3-D visualization, instrumentation with articulating tips that allow for $7^{\circ}$ of movement surpassing the human hands mobility, and in addition if needed a downscaling of the surgeons movements without tremor increasing the accuracy and precision.

Narducci et al. [49] published recently their early experience of robotic-assisted laparoscopy for extraperitoneal paraaortic lymphadenectomy up to the left renal vein. Five patients had a left para-aortic lymphadenectomy and one patient had a complete para-aortic lymphadenectomy. The da Vinci surgical system was positioned at the right shoulder of the patient and the assistant stood on the patient's left side. With this position, infrarenal lymph node dissection has been performed by robotic-assisted laparoscopy. The authors concluded that the technique was safe and effective with a short learning period for an experienced oncological team.

\section{Radical parametrectomy}

Robotic radical parametrectomy is an option treatment for patients with undiagnosed cervical cancer discovered incidentally on a simple hysterectomy specimen. Traditionally, radical parametrectomy has been performed by laparotomy with few cases described by laparoscopicassisted vaginal or total laparoscopic approach $[50,51]$.

Ramirez [52] reported the first five patients treated by robotic radical parametrectomy and pelvic lymphadenectomy. The median operative time was 365 min, estimated blood loss was $100 \mathrm{ml}$, the median number of pelvic lymph nodes was 14, and there were no conversion to laparotomy. There were two postoperative complications (vesicovaginal fistula and lymphocyst) and one intraoperative complication (cystostomy). The authors concluded this operation is feasible and safe and can be performed with an acceptable complication rate.

\section{Radical trachelectomy}

In women with early cervical cancer to preserve fertility, this operation is well established [53-56] and considered to be as safe with laparoscopic pelvic lymphadenectomy. The first report of a robotic radical trachelectomy for fertility sparing in stage $\mathrm{Ib} 1$ adenocarcinoma of the cervix was published by Person et al. [57], who reported two cases of robotic radical trachelectomy and pelvic lymphadenectomy performed in two nullipaurous women with early cervical cancer. The duration of the surgeries was 387 and $358 \mathrm{~min}$, respectively. No perioperative complications were observed. The conclusion of Person was that robotic radical trachelectomy is a safe and feasible alternative to a combined laparoscopic and vaginal approach.

Geisler and Burnett $[58,59]$ published another case with similar results.

\section{Pelvic exenteration}

Minimally invasive surgery may improve the outcome of patients with bulky residual tumors after chemoradiation for locally advanced cervical cancer, and for lateral pelvic wall recurrence. In case of central pelvic recurrence after surgery and adjuvant radiation treatment, pelvic exenteration is the only therapeutic approach with curative goals. The laparoscopy-assisted vaginal pelvic exenteration is feasible [60] with curative intent in selected patients.

Pruthi et al. [61] recently described the technique of robotic-assisted laparoscopic anterior pelvic exenteration performed in 12 women for clinically localized bladder cancer. In all cases, the urinary diversion was performed extracorporeally. Mean operating time was $4.6 \mathrm{~h}$ and the mean surgical blood loss was $221 \mathrm{ml}$. There were two postoperative complications (17\%) in two patients.

\section{Conclusions}

Potential benefits of robotic technology include 3-D, highdefinition optics, instrumentation that allows increased range in motion, precision and scaling, and surgeon autonomy. The mean operating time is longer than laparoscopy but decreases after a short learning curve, even for surgeons with no experience in advanced laparoscopic surgery $[12,31]$. One of the favorable effects of the introduction of robotic surgery has been to lead open surgeons to adopt minimal invasive techniques.

However, robotic surgery is basically laparoscopic surgery. Training in standard laparoscopic surgery is definitely required for several reasons: (1) for simple procedures, the cost of robotic surgery is not acceptable; (2) the robot may not be available any time; (3) in case of technical failure, conversion to standard laparoscopic is preferable to conversion to laparotomy; and (4) the assistant must master the spatial orientation characteristic of laparoscopic surgery-that means that the surgeon cannot leave alone this requirement.

The question of the patient benefit and cost-effectiveness of robotic surgery in centers with prior large laparoscopic experience is still open. The results of a prospective randomized trial comparing abdominal, laparoscopic, and open surgery by surgeons equally experienced in all techniques are needed. 
Declaration of interest The authors report no conflicts of interest. The authors alone are responsible for the content and writing of the paper.

\section{References}

1. Querleu D, Leblanc E, Ferron G, Narducci F, Rafii A, Martel P (2007) Laparoscopic surgery and gynaecological cancers. Bull Cancer 94(12): 1063-1071

2. Beste TM, Nelson KH, Daucher JA (2005) Total laparoscopic hysterectomy utilizing a robotic surgical system. JSLS 9(1):13-15

3. Kho RM, Hilger WS, Hentz JG, Magtibay PM, Magrina JF (2007) Robotic hysterectomy: technique and initial outcomes. Am J Obstet Gynecol 197(1):113-114

4. Advincula AP (2006) Surgical techniques: robot-assisted laparoscopic hysterectomy with the da Vinci surgical system. Int J Med Robot 2(4):305-311

5. Sert BM, Abeler VM (2006) Robotic-assisted laparoscopic radical hysterectomy (Piver type III) with pelvic node dissection-case report. Eur J Gynaecol Oncol 27(5):531-533

6. Reynolds RK, Advincula AP (2006) Robot-assisted laparoscopic hysterectomy: technique and initial experience. Am J Surg 191 (4):555-560

7. Fiorentino RP, Zepeda MA, Goldstein BH, John CR, Rettenmaier MA (2006) Pilot study assessing robotic laparoscopic hysterectomy and patient outcomes. J Minim Invasive Gynecol 13(1):60-63

8. Advincula AP, Reynolds RK (2005) The use of robot-assisted laparoscopic hysterectomy in the patient with a scarred or obliterated anterior cul-de-sac. JSLS 9(3):287-291

9. Fanning J, Fenton B, Purohit M (2008) Robotic radical hysterectomy. Am J Obstet Gynecol 198(6):649-4

10. Kim YT, Kim SW, Hyung WJ, Lee SJ, Nam EJ, Lee WJ (2008) Robotic radical hysterectomy with pelvic lymphadenectomy for cervical carcinoma: a pilot study. Gynecol Oncol 108(2):312-316

11. Oleszczuk A, Kohler C, Paulick J, Schneider A, Lanowska M (2009) Vaginal robot-assisted radical hysterectomy (VRARH) after laparoscopic staging: feasibility and operative results. Int J Med Robot 5(1):38-44

12. Lowe MP, Chamberlain DH, Kamelle SA, Johnson PR, Tillmanns TD (2009) A multi-institutional experience with robotic-assisted radical hysterectomy for early stage cervical cancer. Gynecol Oncol 113(2):191-194

13. Sert B, Abeler V (2007) Robotic radical hysterectomy in earlystage cervical carcinoma patients, comparing results with total laparoscopic radical hysterectomy cases. The future is now? Int J Med Robot 3(3):224-228

14. Magrina JF, Kho RM, Weaver AL, Montero RP, Magtibay PM (2008) Robotic radical hysterectomy: comparison with laparoscopy and laparotomy. Gynecol Oncol 109(1):86-91

15. Maggioni A, Minig L, Zanagnolo V et al (2009) Robotic approach for cervical cancer: comparison with laparotomy: a case-control study. Gynecol Oncol 115(1):60-64

16. Nezhat FR, Datta MS, Liu C, Chuang L, Zakashansky K (2008) Robotic radical hysterectomy versus total laparoscopic radical hysterectomy with pelvic lymphadenectomy for treatment of early cervical cancer. JSLS 12(3):227-237

17. Boggess JF, Gehrig PA, Cantrell L et al (2008) A case-control study of robot-assisted type III radical hysterectomy with pelvic lymph node dissection compared with open radical hysterectomy. Am J Obstet Gynecol 199(4):357

18. bu-Rustum NR, Gemignani ML, Moore K et al (2003) Total laparoscopic radical hysterectomy with pelvic lymphadenectomy using the argon-beam coagulator: pilot data and comparison to laparotomy. Gynecol Oncol 91(2):402-409
19. Querleu D (1993) Laparoscopically assisted radical vaginal hysterectomy. Gynecol Oncol 51(2):248-254

20. Frumovitz M, dos Reis R, Sun CC et al (2007) Comparison of total laparoscopic and abdominal radical hysterectomy for patients with early-stage cervical cancer. Obstet Gynecol 110(1):96-102

21. Zakashansky K, Lerner DL (2008) Total laparoscopic radical hysterectomy for the treatment of cervical cancer. J Minim Invasive Gynecol 15(3):387-388

22. Obermair A, Gebski V, Frumovitz M et al (2008) A phase III randomized clinical trial comparing laparoscopic or robotic radical hysterectomy with abdominal radical hysterectomy in patients with early stage cervical cancer. J Minim Invasive Gynecol 15 (5):584-588

23. Veljovich DS, Paley PJ, Drescher CW, Everett EN, Shah C, Peters WA III (2008) Robotic surgery in gynecologic oncology: program initiation and outcomes after the first year with comparison with laparotomy for endometrial cancer staging. Am J Obstet Gynecol 198(6):679

24. Bell MC, Torgerson J, Seshadri-Kreaden U, Suttle AW, Hunt S (2008) Comparison of outcomes and cost for endometrial cancer staging via traditional laparotomy, standard laparoscopy and robotic techniques. Gynecol Oncol 111(3):407-411

25. Frigerio L, Gallo A, Ghezzi F, Trezzi G, Lussana M, Franchi M (2006) Laparoscopic-assisted vaginal hysterectomy versus abdominal hysterectomy in endometrial cancer. Int $\mathrm{J}$ Gynaecol Obstet 93(3):209-213

26. Eltabbakh GH, Shamonki MI, Moody JM, Garafano LL (2000) Hysterectomy for obese women with endometrial cancer: laparoscopy or laparotomy? Gynecol Oncol 78(3 Pt 1):329-335

27. Gil-Moreno A, az-Feijoo B, Morchon S, Xercavins J (2006) Analysis of survival after laparoscopic-assisted vaginal hysterectomy compared with the conventional abdominal approach for early-stage endometrial carcinoma: a review of the literature. $\mathrm{J}$ Minim Invasive Gynecol 13(1):26-35

28. Denardis SA, Holloway RW, Bigsby GE, Pikaart DP, Ahmad S, Finkler NJ (2008) Robotically assisted laparoscopic hysterectomy versus total abdominal hysterectomy and lymphadenectomy for endometrial cancer. Gynecol Oncol 111(3):412-417

29. Boggess JF, Gehrig PA, Cantrell L et al (2008) A comparative study of 3 surgical methods for hysterectomy with staging for endometrial cancer: robotic assistance, laparoscopy, laparotomy. Am J Obstet Gynecol 199(4):360-369

30. Hoekstra AV, Jairam-Thodla A, Rademaker A et al (2009) The impact of robotics on practice management of endometrial cancer: transitioning from traditional surgery. Int J Med Robot 5(4):392397

31. Lowe MP, Johnson PR, Kamelle SA, Kumar S, Chamberlain DH, Tillmanns TD (2009) A multiinstitutional experience with roboticassisted hysterectomy with staging for endometrial cancer. Obstet Gynecol 114(2 Pt 1):236-243

32. Kohler C, Klemm P, Schau A et al (2004) Introduction of transperitoneal lymphadenectomy in a gynecologic oncology center: analysis of 650 laparoscopic pelvic and/or paraaortic transperitoneal lymphadenectomies. Gynecol Oncol 95(1):5261

33. Seamon LG, Cohn DE, Henretta MS et al (2009) Minimally invasive comprehensive surgical staging for endometrial cancer: robotics or laparoscopy? Gynecol Oncol 113(1):36-41

34. Scribner DR Jr, Walker JL, Johnson GA, McMeekin SD, Gold MA, Mannel RS (2001) Surgical management of early-stage endometrial cancer in the elderly: is laparoscopy feasible? Gynecol Oncol 83(3):563-568

35. Occelli B, Narducci F, Lanvin D, Leblanc E, Querleu D (2000) Learning curves for transperitoneal laparoscopic and extraperitoneal endoscopic paraaortic lymphadenectomy. J Am Assoc Gynecol Laparosc 7(1):51-53 
36. Holub Z, Jabor A, Bartos P, Hendl J, Urbanek S (2003) Laparoscopic surgery in women with endometrial cancer: the learning curve. Eur J Obstet Gynecol Reprod Biol 107(2):195200

37. Querleu D, Dargent D, Ansquer Y, Leblanc E, Narducci F (2000) Extraperitoneal endosurgical aortic and common iliac dissection in the staging of bulky or advanced cervical carcinomas. Cancer 88 (8):1883-1891

38. Kehoe SM, bu-Rustum NR (2006) Transperitoneal laparoscopic pelvic and paraaortic lymphadenectomy in gynecologic cancers. Curr Treat Options Oncol 7(2):93-101

39. Marnitz S, Kohler C, Roth C, Fuller J, Hinkelbein W, Schneider A (2005) Is there a benefit of pretreatment laparoscopic transperitoneal surgical staging in patients with advanced cervical cancer? Gynecol Oncol 99(3):536-544

40. Papadia A, Remorgida V, Salom EM, Ragni N (2004) Laparoscopic pelvic and paraaortic lymphadenectomy in gynecologic oncology. J Am Assoc Gynecol Laparosc 11(3):297-306

41. Magrina JF (2007) Robotic surgery in gynecology. Eur J Gynaecol Oncol 28(2):77-82

42. Holloway RW, Ahmad S, Denardis SA et al (2009) Roboticassisted laparoscopic hysterectomy and lymphadenectomy for endometrial cancer: analysis of surgical performance. Gynecol Oncol 115(3):447-452

43. Burnett AF, O'Meara AT, Bahador A, Roman LD, Morrow CP (2004) Extraperitoneal laparoscopic lymph node staging: the University of Southern California experience. Gynecol Oncol 95(1):189-192

44. Tillmanns T, Lowe MP (2007) Safety, feasibility, and costs of outpatient laparoscopic extraperitoneal aortic nodal dissection for locally advanced cervical carcinoma. Gynecol Oncol 106(2):370-374

45. Gil-Moreno A, Franco-Camps S, az-Feijoo B et al (2008) Usefulness of extraperitoneal laparoscopic paraaortic lymphadenectomy for lymph node recurrence in gynecologic malignancy. Acta Obstet Gynecol Scand 87(7):723-730

46. Vergote I, Pouseele B, Van GT et al (2008) Robotic retroperitoneal lower para-aortic lymphadenectomy in cervical carcinoma: first report on the technique used in 5 patients. Acta Obstet Gynecol Scand 87(7):783-787

47. Michel G, Morice P, Castaigne D, Leblanc M, Rey A, Duvillard P (1998) Lymphatic spread in stage Ib and II cervical carcinoma: anatomy and surgical implications. Obstet Gynecol 91(3):360-363

48. edetti-Panici P, Maneschi F, Scambia G, Cutillo G, Greggi S, Mancuso S (1996) The pelvic retroperitoneal approach in the treatment of advanced ovarian carcinoma. Obstet Gynecol 87 (4):532-538
49. Narducci F, Lambaudie E, Houvenaeghel G, Collinet P, Leblanc E (2009) Early experience of robotic-assisted laparoscopy for extraperitoneal para-aortic lymphadenectomy up to the left renal vein. Gynecol Oncol 115(1):172-174

50. Nezhat F, Prasad HM, Peiretti M, Rahaman J (2007) Laparoscopic radical parametrectomy and partial vaginectomy for recurrent endometrial cancer. Gynecol Oncol 104(2):494-496

51. Lee CL, Huang KG (2005) Total laparoscopic radical parametrectomy. J Minim Invasive Gynecol 12(2):168-170

52. Ramirez PT, Schmeler KM, Wolf JK, Brown J, Soliman PT (2008) Robotic radical parametrectomy and pelvic lymphadenectomy in patients with invasive cervical cancer. Gynecol Oncol 111 (1):18-21

53. Shepherd JH, Spencer C, Herod J, Ind TE (2006) Radical vaginal trachelectomy as a fertility-sparing procedure in women with early-stage cervical cancer-cumulative pregnancy rate in a series of 123 women. BJOG 113(6):719-724

54. Diaz JP, Sonoda Y, Leitao MM et al (2008) Oncologic outcome of fertility-sparing radical trachelectomy versus radical hysterectomy for stage IB1 cervical carcinoma. Gynecol Oncol 111(2):255-260

55. Einstein MH, Park KJ, Sonoda Y et al (2009) Radical vaginal versus abdominal trachelectomy for stage IB1 cervical cancer: a comparison of surgical and pathologic outcomes. Gynecol Oncol 112(1):73-77

56. Beiner ME, Hauspy J, Rosen B et al (2008) Radical vaginal trachelectomy vs. radical hysterectomy for small early stage cervical cancer: a matched case-control study. Gynecol Oncol 110(2):168-171

57. Persson J, Kannisto P, Bossmar T (2008) Robot-assisted abdominal laparoscopic radical trachelectomy. Gynecol Oncol 111 (3):564-567

58. Burnett AF, Stone PJ, Duckworth LA, Roman JJ (2009) Robotic radical trachelectomy for preservation of fertility in early cervical cancer: case series and description of technique. J Minim Invasive Gynecol 16(5):569-572

59. Geisler JP, Orr CJ, Manahan KJ (2008) Robotically assisted total laparoscopic radical trachelectomy for fertility sparing in stage IB1 adenosarcoma of the cervix. J Laparoendosc Adv Surg Tech A $18(5): 727-729$

60. Ferron G, Querleu D, Martel P, Letourneur B, Soulie M (2006) Laparoscopy-assisted vaginal pelvic exenteration. Gynecol Oncol 100(3):551-555

61. Pruthi RS, Stefaniak H, Hubbard JS, Wallen EM (2008) Robotassisted laparoscopic anterior pelvic exenteration for bladder cancer in the female patient. J Endourol 22(10):2397-2402 